\title{
Netupitant/palonosetron without dexamethasone for preventing nausea and vomiting in patients with multiple myeloma receiving high-dose melphalan for autologous stem cell transplantation: a single-center experience
}

\author{
Barbara Loteta ${ }^{1}$. Annalisa Paviglianiti ${ }^{1}$. Virginia Naso ${ }^{1}$ Anna Ferreri ${ }^{1}$. Tiziana Moscato ${ }^{1}$. Giuseppe Console ${ }^{1}$. \\ Filippo Antonio Canale ${ }^{1}$. Giuseppe Irrera ${ }^{1}$. Marta Pugliese ${ }^{1}$ - Antonella Di Costanzo ${ }^{2}$. Pasquale Fabio Provenzano ${ }^{1}$. \\ Viviana Loddo ${ }^{3}$. Gaetana Porto ${ }^{1}$. Giuseppa Cusumano ${ }^{1}$. Letteria Russo ${ }^{1}$. Nicola Meliambro' ${ }^{1}$ Valentina Romeo ${ }^{1}$. \\ Domenico Porcino ${ }^{1}$ Salvatore Gallo ${ }^{1}$. Tiziana Gangemi ${ }^{1}$. Antonio Maria Rossetti ${ }^{1}$ Massimo Martino ${ }^{1}$ (i)
}

Received: 22 April 2021 / Accepted: 24 July 2021 / Published online: 4 August 2021

(c) The Author(s), under exclusive licence to Springer-Verlag GmbH Germany, part of Springer Nature 2021

\begin{abstract}
Chemotherapy-induced nausea and vomiting (CINV) is one of the most frequent adverse events compromising quality of life (QoL) in patients undergoing autologous stem cell transplantation (ASCT). However, CINV prophylaxis is still lacking uniformity for high-dose melphalan (HDM), which is used to condition patients with multiple myeloma (MM). Netupitant/palonosetron (NEPA) is administered with dexamethasone (DEXA) for CINV prevention in several chemotherapy regimens. Our study aims to assess the efficacy of NEPA, without DEXA, in preventing CINV in 106 adult patients with MM receiving HDM and ASCT. All patients had antiemetic prophylaxis with multiple doses of NEPA $1 \mathrm{~h}$ before the start of conditioning and after $72 \mathrm{~h}$ and $120 \mathrm{~h}$. A complete response (CR) was observed in 99 (93\%) patients at $120 \mathrm{~h}$ (overall phase). The percentage of patients with complete control was 93\%. The CR rate during the acute phase was $94 \%(n=100)$. During the delayed phase, the CR rate was $95 \%(n=101)$. Grade 1 nausea and vomiting were experienced by $82 \%$ and $12 \%$ of the patients, respectively. Grade 2 nausea was reported in $18 \%$ and vomiting in $10 \%$ of patients. Our results showed, for the first time, that NEPA, without DEXA, was a well-tolerated and effective antiemetic option for MM patients receiving HDM followed by ASCT.
\end{abstract}

Keywords Chemotherapy-induced nausea and vomiting (CINV) $\cdot$ Netupitant/palonosetron (NEPA) $\cdot$ High-dose melphalan · ASCT $\cdot$ Multiple myeloma

\section{Introduction}

A highly emetogenic chemotherapy (HEC) regimen is widely used as a conditioning regimen for patients with multiple myeloma (MM) undergoing autologous stem

Massimo Martino

massimo.martino@ospedalerc.it

1 Stem Cell Transplant and Cellular Therapies Unit, Hemato-Oncology and Radiotherapy Department, Grande Ospedale Metropolitano "Bianchi-Melacrino-Morelli", Viale Europa, 89133 Reggio Calabria, Italy

2 Medical Affairs Department, Italfarmaco SpA, Milan, Italy

3 Catholic University of the Sacred Heart, Rome, Italy cell transplantation (ASCT) [6]. Chemotherapy-induced nausea and vomiting (CINV) still represents the most distressing side effects, and nausea is reported by more than $50 \%$ of the patients undergoing a transplant [22]. The problem of controlling CINV in ASCT recipients is far from solved [23]. The cause of CINV in ASCT is related to many factors, such as gender, age, number of previous chemotherapy lines, and the use of prophylactic antibiotics and narcotic analgesics in the management of mucositis [15, 29]. CINV may also be influenced by factors related to treatment including conditioning regimens, administration, dose, duration, and schedule of the drugs, along with the possible additive effect of several chemotherapy drugs [27]. Uncontrolled CINV can be detrimental for the patient and cause metabolic alterations, 
such as dehydration, electrolyte imbalance, and malnutrition, and therefore interfere with patient adherence to life-saving treatments.

Melphalan (MEL) remains the most widely used agent in preparative regimens for both ASCT and allogeneic transplants because of its myeloablative properties and broad antitumor effects as a DNA alkylating agent [4]. MM remains the main indication for ASCT worldwide $[8,28]$. The current standard approach for ASCT in MM patients is to use high-dose MEL (HDM) $200 \mathrm{mg} /$ $\mathrm{m}^{2}$ except in those aged over 70 and those with kidney failure, for whom a lower dose of HDM is used (140 mg/ $\left.\mathrm{m}^{2}\right)[16,24]$. However, very little information is available about its potential impact on the onset of nausea and vomiting in these patients [33]. The National Comprehensive Cancer Network (NCCN) guidelines recently included parenteral $\mathrm{HDM} \geq 140 \mathrm{mg} / \mathrm{m}^{2}$ in patients with a high emetic risk, and MEL $<140 \mathrm{mg} / \mathrm{m}^{2}$ in those with a moderate emetic risk [12].

Palonosetron (PALO) with aprepitant, low-dose dexamethasone (DEXA), and olanzapine have been used for preventing nausea and vomiting in patients with MM undergoing ASCT [21, 26, 36]. While these studies have reported a low incidence of emesis $(0-41 \%)$, other studies have reported delayed vomiting as moderately frequent (12-66\%), despite adequate prophylaxis in patients receiving HDM [5, 9]. Recently, Tendas et al. showed that an aprepitant-based, three-drug regimen (aprepitant + serotonin receptor antagonist (5HT3RA) + DEXA) had a better efficacy than a two-drug regimen (5HT3RA+DEXA) without increasing the frequency of adverse events for CINV prophylaxis in MM patients undergoing ASCT with HDM conditioning [12].

Netupitant/palonosetron (NEPA) is the first oral fixed combination of a highly selective Neurokinin 1 (NK1) receptor antagonist (RA) with the second-generation 5-HT3 RA PALO. NEPA has demonstrated superiority in preventing CINV compared with PALO in patients receiving cisplatin and anthracycline/cyclophosphamide-based chemotherapy $[2,19]$.

A limited number of published studies have reported the impact of NEPA in preventing nausea and vomiting in patients receiving ASCT. Recently, Di Renzo et al. reported the use of NEPA without DEXA in 82 patients undergoing ASCT for NHL[14]. Apolito et al. [3] described 70 patients who underwent ASCT for MM and received NEPA in combination with DEXA before ASCT. However, no published studies report the use of NEPA without DEXA in MM patients receiving HDM and ASCT. We, therefore, evaluated the efficacy of NEPA, without DEXA, for CINV prophylaxis in 106 patients who underwent ASCT for MM.

\section{Patients and methods}

\section{Study design}

This is a single-center, open-label, prospective, observational study designed to assess the efficacy of NEPA in preventing acute and delayed CINV in patients with MM receiving HDM and ASCT. The local ethics committee approved the study, and all patients signed the informed consent form in accordance with the Declaration of Helsinki and the International Conference on Harmonization Guidelines for Good Clinical Practice.

\section{Patients}

The inclusion criteria were patients aged $\geq 18$ years with a diagnosis of MM, eligible for transplantation, a favorable response (according to the International Myeloma Working Group criteria after induction therapy), and a World Health Organization performance status of 0 to 3 .

\section{Treatment}

All patients received a bortezomib-based induction therapy in combination with thalidomide, and dexamethasone (VTD) or cyclophosphamide, and dexamethasone (VCD). Highdose cyclophosphamide $\left(2-4 \mathrm{~g} / \mathrm{m}^{2}\right)$ plus granulocyte colony-stimulating factor was used to mobilize peripheral blood stem cells. For the transplant phase, patients were admitted to hospital in a positive-pressure, reverse-isolation room and followed a "complete inpatient" program comprising central venous catheter implantation on day -2 , conditioning regimen on day -1 , stem cell reinfusion on day 0 , and supportive care during the aplastic phase. The conditioning regimen was high-dose melphalan (HDM) $200 \mathrm{mg} / \mathrm{m}^{2}$, given on day -1 , with a single intravenous infusion lasting 30 min. Day 0 was the day of ASCT. During the aplastic phase, patients received oral prophylaxis with ciprofloxacin (500 $\mathrm{mg}$ twice daily) or levofloxacin (500 mg daily from day 0 until neutrophil count recovery) and acyclovir (800 mg twice daily from day +3 ). Granulocyte colony-stimulating factor (pegfilgrastim) was administered on day +1 . Red blood cell and platelet transfusions were performed when indicated to maintain the hemoglobin level at $\geq 8 \mathrm{~g} / \mathrm{dL}$ and the platelet count at $\geq 10 \times 10^{9} / \mathrm{L}$, or in the presence of symptomatic anemia and/or minimal mucocutaneous bleeding. Patients also received continuous i.v. hydration and electrolyte support. The time to neutrophil engraftment was defined as the interval between day 0 and the first of 3 consecutive days of an ANC $>0.5 \times 10^{9} / \mathrm{L}$ after transplantation. The time to platelet engraftment was defined as the interval between 
day 0 and the first day of a platelet count $>20 \times 10^{9} / \mathrm{L}$ in the absence of platelet transfusions within the previous 7 days.

\section{Antiemetic prophylaxis}

NEPA was administered at a dose of 1 capsule $(300 \mathrm{mg}$ netupitant; $0.5 \mathrm{mg}$ palonosetron) $1 \mathrm{~h}$ before the start of chemotherapy conditioning (day -1$)$ and repeated after $72 \mathrm{~h}$ $($ day +2$)$ and after $120 \mathrm{~h}($ day +4$)$. Intravenous levosulpiride $25 \mathrm{mg}$ was used as a rescue antiemetic when needed. All patients underwent oral cryotherapy for the prevention of mucositis during the administration of MEL.

\section{Assessment}

For 10 days after HDM infusion, the nurses recorded emetic episodes and rated nausea daily. In the $2 \mathrm{~h}$ prior to starting chemotherapy, patients recorded whether or not they had suffered from vomiting and the rate of nausea in the previous $24 \mathrm{~h}$. The investigators reviewed the diary in order to ensure the completeness of the data. Rescue therapy (defined as any medication taken to treat established nausea or emesis) was recorded after reviewing the medical and nursing charts. Nausea and vomiting were graded according to the Common Terminology Criteria for Adverse Events (CTCAE) 4.03.

\section{Endpoints and statistical analysis}

The primary endpoint was the rate of complete response (no emesis and no rescue medication) (CR) at $120 \mathrm{~h}$ after conditioning. Secondary endpoints were defined as the rate of CR during the acute phase $(0-24 \mathrm{~h})$ and delayed phase (25-120 h) from the start of HDM. Patients were evaluated every day for up to 10 days after ASCT. The occurrence of breakthrough emesis after $72 \mathrm{~h}$ was considered a treatment failure. The safety of NEPA was also evaluated. Qualitative variable data were expressed as frequencies and percentages and were evaluated using the chi-square test. Analyses were performed with SPSS 19 (IBM SPSS Statistics for Windows, version 19.0, IBM Corp, Armonk, NY).

\section{Results}

A total of 106 patients were enrolled. The main patient characteristics and transplant outcomes are summarized in Table 1 . The median age was 60 (range: $42-72$ ) years. Sixtyseven (63\%) patients were male and the Eastern Cooperative Oncology Group (ECOG) performance status was $\leq 1$ in 100 (96\%). The median body weight was 72.5 (range: 43-170) $\mathrm{kg}$. No treatment-related mortality was registered.

NEPA prophylaxis showed a high efficacy in preventing CINV during the HDM conditioning period, especially for no emesis and no rescue therapy with a proportion of patients of $93.4 \%$ and $98 \%$ in the overall phase (supplementary table 1), respectively. The primary outcome was largely achieved with a CR observed in 99 (93.3\%) patients at $120 \mathrm{~h}$. The CR rate during the acute phase was $94.3 \%(n=100)$. During the delayed phase, the CR rate was $95.2 \%(n=101)$ (Fig. 1). The percentage of patients who attained complete control in the overall phase was $93 \%$. Grade 1 nausea and vomiting were experienced by $82 \%$ and $12 \%$ of the patients, respectively. Grade 2 nausea was reported in $18 \%$ and vomiting in $10 \%$ of patients. No patients had grade 3-4 nausea or vomiting (Fig. $2 \mathrm{a}$ and $\mathrm{b}$ ). Breakthrough emesis occurred in $2 \%$ of the patients, who received levosulpiride as a salvage treatment (supplementary table 1). Only one patient $\mathrm{had}>2$ episodes of vomiting during the first $24 \mathrm{~h}$, but he did not require second-line antiemetic therapy. In all, $71(67 \%)$ patients experienced weight loss at 7 days after ASCT. The median body weight loss was 2 (range: $0.5-8$ ) $\mathrm{kg}$. NEPA showed a good safety profile, resulting in very well tolerated with no TEAEs occurring.

\section{Discussion}

Uncontrolled nausea and vomiting still remain two of the main, disabling symptoms for patients undergoing chemotherapy. Several complications such as weight loss, electrolyte imbalance, dehydration, and weakness impair not only the patients' health but also their quality of life. Management of CINV in ASCT is challenging [34, 35] and the guidelines in multiple day/drug regimens, commonly used in conditioning regimens, are very difficult to apply [30]. Over the past few years, several clinical studies have reported the efficacy of the combination of three drugs, 5HT3RA, NK1RA, and dexamethasone, for antiemetic prophylaxis [19, 20]. Although the superior efficacy of the triple-antiemetic regimen has been widely reported in the literature, adherence to the international antiemetic guidelines (MASCC/ ESMO) is still low resulting in a lack of compliance and poor prophylaxis for the patients [5]. The HDM $200 \mathrm{mg} / \mathrm{m}^{2}$ regimen, which is the "gold standard" in MM patients [10, 11], requires a single-day administration of chemotherapy. Recently, the National Comprehensive Cancer Network $(\mathrm{NCCN})$ guidelines placed intravenous melphalan $\geq 140 \mathrm{mg} /$ $\mathrm{m}^{2}$ in the highly emetogenic category (>90\%) [13]. Consequently, CINV prophylaxis should be designed with the three-drug (aprepitant, 5HT3RA, dexamethasone) or fourdrug (olanzapine, aprepitant, 5HT3RA, dexamethasone) combinations in accordance with the recommended guidelines for patients undergoing ASCT [24].

In the HDM setting, palonosetron [9, 11, 17, 20, 25, 26], granisetron [21, 32, 37], and ondansetron [5, 7, 36] have been investigated. None of the aforementioned studies was 
Table 1 Patient characteristics and transplant outcomes

\begin{tabular}{|c|c|}
\hline Variable & Value \\
\hline No. of patients & 106 \\
\hline Age, years, median (range) & $60(42-70)$ \\
\hline Median weight, range, kg & $72.5(43-170)$ \\
\hline \multicolumn{2}{|l|}{ Gender } \\
\hline Male & $67(63 \%)$ \\
\hline Female & $39(37 \%)$ \\
\hline \multicolumn{2}{|l|}{ ECOG } \\
\hline $0-1$ & $100(94 \%)$ \\
\hline $2-3$ & $6(6 \%)$ \\
\hline \multicolumn{2}{|l|}{ Induction therapy } \\
\hline Bortezomib, thalidomide, and dexamethasone (VTD) & $96(91 \%)$ \\
\hline Bortezomib, cyclophosphamide, and dexamethasone (VCD) & $10(9 \%)$ \\
\hline \multicolumn{2}{|l|}{ Mobilization regimen } \\
\hline Cyclophosphamide $2 \mathrm{~g} / \mathrm{m}^{2}+\mathrm{G}-\mathrm{CSF}$ & $106(100 \%)$ \\
\hline \multicolumn{2}{|l|}{ Conditioning regimen } \\
\hline Melphalan 200 mg/m² & $106(100 \%)$ \\
\hline \multicolumn{2}{|l|}{ Disease status before ASCT } \\
\hline $\mathrm{CR}$ & $25(23.5 \%)$ \\
\hline VGPR & $61(58.4 \%)$ \\
\hline PR & $19(16.4 \%)$ \\
\hline No. of CD34 + infused (106/kg) & $4.35(3.8-5.1)$ \\
\hline Incidence of febrile neutropenia & $28 \%$ \\
\hline Among patients with fever-days with fever $\left(\geq 38.2^{\circ} \mathrm{C}\right)$ & $3(2-4)$ \\
\hline \multicolumn{2}{|l|}{ Mucositis } \\
\hline Yes (WHO 0-1) & $69 \%$ \\
\hline Yes (WHO 2-3) & $31 \%$ \\
\hline \multicolumn{2}{|l|}{ Diarrhea } \\
\hline Yes (WHO 0-1) & $84 \%$ \\
\hline Yes (WHO 2-3) & $16 \%$ \\
\hline \multicolumn{2}{|l|}{ Red blood cell transfusions } \\
\hline No & $81 \%$ \\
\hline Yes & $19 \%$ \\
\hline Among patients with red blood cell transfusions & $1(1-2)$ \\
\hline \multicolumn{2}{|l|}{ Platelet transfusions } \\
\hline No & $44 \%$ \\
\hline Yes & $56 \%$ \\
\hline Among patients with platelet transfusions & $2(1-29)$ \\
\hline Days to $\mathrm{ANC} \geq 0.5 \times 10^{9} \mathrm{~L}$ & $10(9-10)$ \\
\hline Days to reach platelet count $\geq 20 \times 10[9] / \mathrm{L}$ & $13(12-15)$ \\
\hline Days to discharge (after stem cell infusion) & $16(15-19)$ \\
\hline
\end{tabular}

The table reports age, gender, the ECOG performance status, and the chemotherapy regimen administered to all 106 patients enrolled in the study. Abbreviations: ASCT, autologous stem cell transplantation; ECOG, Eastern Cooperative Oncology Group; $C R$, complete remission; VGPR, very good partial remission; $P R$, partial remission randomized and the three drugs can be considered equivalent in terms of efficacy for CINV prevention. In terms of side effects, palonosetron has a better safety profile, as it does not cause heart problems, in particular QTc prolongation [18]. Recently, Tendas et al. reviewed the literature for emetogenicity and the efficacy and safety of CINV during ASCT with HDM conditioning, and concluded that the aprepitant-based three-drug regimen should be the regimen of choice for CINV prophylaxis in these patients, although the heterogeneity of the studies examined does not allow definitive conclusions to be drawn [33].

DEXA is recommended for CINV prophylaxis in ASCT in combination with 5HT3RA and aprepitant. Although the exact mechanism of action of DEXA in CINV prevention is 
Fig. 1 Proportions of patients with complete response (no emesis and no rescue medication) and no emesis for the acute (0-24 h), delayed (25-120 h), and overall $(0-120 \mathrm{~h})$ phases

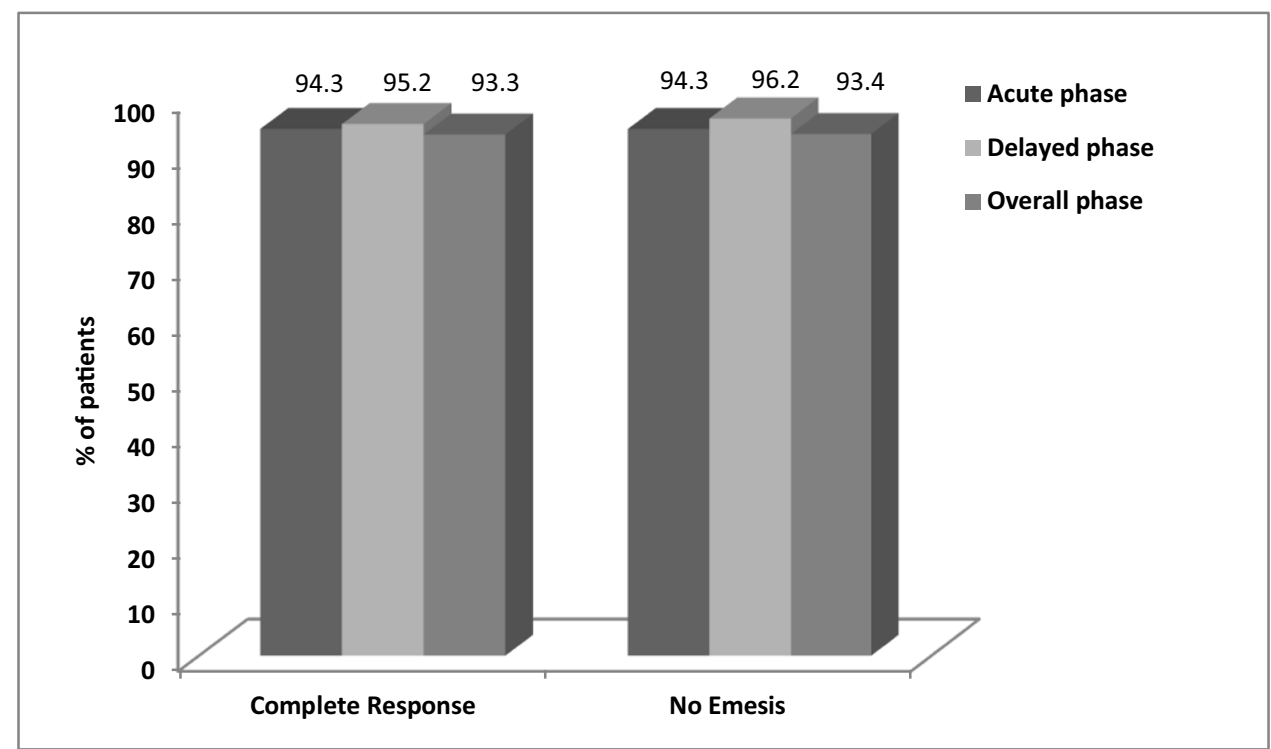

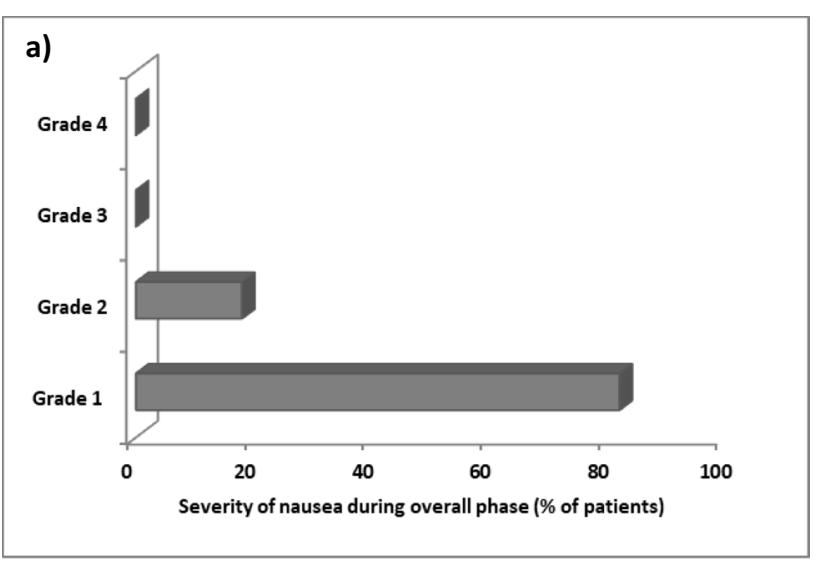

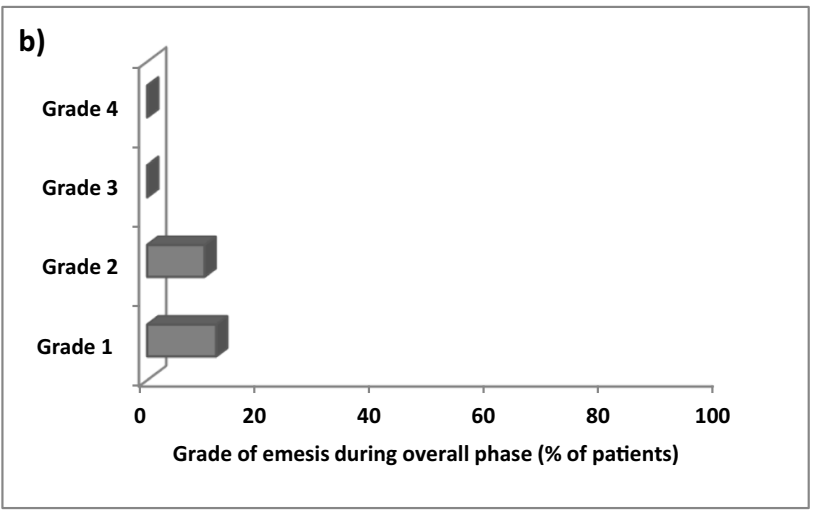

Fig. 2 The histograms show the proportions of patients with grade 1, grade 2, grade 3, and grade 4 of nausea (a) and emesis (b) during overall phase $(120 \mathrm{~h})$ according to the Common Terminology Criteria for Adverse Events (CTCAE) 4.03

unclear, guidelines strongly recommend its administration as CINV prophylaxis $[12,30]$. However, the use of DEXA is associated with numerous side effects, such as increased immunosuppression, a higher risk of infections, dysmetabolic alterations, and adrenal insufficiency with suppression of the hypothalamic-pituitary-adrenal axis [10,31].

Guidelines for CINV prophylaxis recommend the use of olanzapine in high emetic risk chemotherapy, but the advantage of its use in high-dose chemotherapy with ASCT is not clear $[13,16,25]$.

The rationale of our study was to explore the efficacy and the safety of NEPA (given as single agent, on days $-1,+2$, and +4 ) without DEXA in preventing CINV in patients with MM and treated with HDM $200 \mathrm{mg} / \mathrm{m}^{2}$ and ASCT. We observed a safe and excellent control of CINV in this cohort of patients treated with a single oral administration with good compliance. NEPA administration resulted in a very high complete response rate during the acute (94.3\%), delayed (95.2\%), and overall (93.3\%) phases. In a similar study, Apolito et al. reported the same type of disease and conditioning regimen but patients received only 1 day of NEPA in combination with $10 \mathrm{mg}$ DEXA [22]. The short duration and schedule may explain the significant difference in the overall CR rate: $56 \%$ compared to $93 \%$ obtained in our cohort. The use, in our study, of a one-dose drug administration combined an effective antiemetic prophylaxis with a simplification of the therapy, which also enables the use of DEXA in heavily pre-treated and immunocompromised patients to be avoided [1]. In fact, despite the known properties of DEXA for the treatment of patients with MM, its equally known immunosuppressive activity must be evaluated in the management of transplant patients at a high risk of infectious complications. In addition, as recently reported by the ESMO guidance for supportive care, the use of DEXA during this pandemic should be reviewed in patients with established cancer and at a high risk of COVID-19 complications [13]. 
In conclusion, for the first time, our study provides evidence of the high efficacy of NEPA without DEXA in controlling both emesis and nausea in patients at a high risk of CINV undergoing HDM.

Supplementary Information The online version contains supplementary material available at https://doi.org/10.1007/s00520-021-06472-7.

Acknowledgements The authors thank all the nurses and data managers that provided data for this study.

Author contribution BL and MM designed the study. AP, BL, ADC, and $\mathrm{MM}$ wrote the manuscript. AP, PFP, VL, and GP performed the statistical analysis. BL, VN, AF, FAC, MP, TM, GC, FAC, GI, MP, and MM provided cases for the study. FP, GC, LR, NM, VR, DP, SG, TG, and AMR administered the daily questionnaire and sorted the data in nurse files. All the authors edited and approved the final version of the manuscript.

\section{Data availability N/A}

Code availability N/A

\section{Declarations}

Ethics approval All procedures performed in studies involving human participants were in accordance with the ethical standards of Support Care Cancer institutional research committee and the 1964 Declaration of Helsinki and its later amendments or comparable ethical standards.

Consent to participate Informed consent was obtained from all individual participants included in the study.

\section{Consent for publication N/A}

Conflict of interest ADC is an employee of Italfarmaco SpA. Other authors have no conflict of interest to disclose.

\section{References}

1. Aapro M, Ruffo P, Panteri R, Costa S, Piovesana V (2018) Oncologist perspectives on chemotherapy-induced nausea and vomiting (CINV) management and outcomes: a quantitative market research-based survey. Cancer Rep (Hoboken) 1:e1127

2. Aapro M, Rugo H, Rossi G, Rizzi G, Borroni ME, Bondarenko I, Sarosiek T, Oprean C, Cardona-Huerta S, Lorusso V, Karthaus M, Schwartzberg L, Grunberg S (2014) A randomized phase III study evaluating the efficacy and safety of NEPA, a fixed-dose combination of netupitant and palonosetron, for prevention of chemotherapy-induced nausea and vomiting following moderately emetogenic chemotherapy. Ann Oncol 25:1328-1333

3. Apolito V, Giaccone L, Ferrero S, Larocca A, Cavallo F, Coscia M, Beggiato E, Butera S, Martella F, Dainese C, Cetani G, Scaldaferri M, Cattel F, Boccadoro M, Ferrero D, Bruno B, Cerrano M (2020) Netupitant-palonosetron to prevent chemotherapy-induced nausea and vomiting in multiple myeloma patients receiving high-dose melphalan and autologous stem cell transplantation. Ann Hematol 99:2197-2199
4. Bayraktar UD, Bashir Q, Qazilbash M, Champlin RE, Ciurea SO (2013) Fifty years of melphalan use in hematopoietic stem cell transplantation. Biol Blood Marrow Transplant 19:344-356

5. Bechtel T, McBride A, Crawford B, Bullington S, Hofmeister CC, Benson DM Jr, Jaglowski S, Penza S, Andritsos LA, Devine SM (2014) Aprepitant for the control of delayed nausea and vomiting associated with the use of high-dose melphalan for autologous peripheral blood stem cell transplants in patients with multiple myeloma: a phase II study. Support Care Cancer 22:2911-2916

6. Child JA, Morgan GJ, Davies FE, Owen RG, Bell SE, Hawkins K, Brown J, Drayson MT, Selby PJ, Medical Research Council Adult Leukaemia Working P (2003) High-dose chemotherapy with hematopoietic stem-cell rescue for multiple myeloma. $\mathrm{N}$ Engl J Med 348:1875-1883

7. Clark SM, Clemmons AB, Schaack L, Garren J, DeRemer DL, Kota VK (2016) Fosaprepitant for the prevention of nausea and vomiting in patients receiving BEAM or high-dose melphalan before autologous hematopoietic stem cell transplant. J Oncol Pharm Pract 22:416-422

8. D'Souza A, Fretham C, Lee SJ, Arora M, Brunner J, Chhabra S, Devine S, Eapen M, Hamadani M, Hari P, Pasquini MC, Perez W, Phelan RA, Riches ML, Rizzo JD, Saber W, Shaw BE, Spellman SR, Steinert P, Weisdorf DJ, Horowitz MM (2020) Current use of and trends in hematopoietic cell transplantation in the United States. Biol Blood Marrow Transplant 26:e177-e182

9. Deauna-Limayo D, Aljitawi OS, Ganguly S, Abhyankar S, Wick JA, McGuirk JP (2014) Combined use of multiday palonosetron with aprepitant and low-dose dexamethasone in prevention of nausea and emesis among patients with multiple myeloma and lymphoma undergoing autologous hematopoietic stem cell transplant: a pilot study. J Oncol Pharm Pract 20:263-269

10. Decramer M, Lacquet LM, Fagard R, Rogiers P (1994) Corticosteroids contribute to muscle weakness in chronic airflow obstruction. Am J Respir Crit Care Med 150:11-16

11. Del Gaudio N, Di Costanzo A, Liu NQ, Conte L, Migliaccio A, Vermeulen M, Martens JHA, Stunnenberg HG, Nebbioso A, Altucci L (2019) BRD9 binds cell type-specific chromatin regions regulating leukemic cell survival via STAT5 inhibition. Cell Death Dis $10: 338$

12. Di Costanzo A, Del Gaudio N, Conte L, Dell'Aversana C, Vermeulen M, de The H, Migliaccio A, Nebbioso A, Altucci L (2018) The HDAC inhibitor SAHA regulates CBX2 stability via a SUMO-triggered ubiquitin-mediated pathway in leukemia. Oncogene 37:2559-2572

13. Di Costanzo A, Troiano A, di Martino O, Cacace A, Natale CF, Ventre M, Netti P, Caserta S, Pollice A, La Mantia G, Calabro V (2012) The p63 protein isoform DeltaNp63alpha modulates Y-box binding protein 1 in its subcellular distribution and regulation of cell survival and motility genes. J Biol Chem 287:30170-30180

14. Di Renzo N, Musso M, Scime R, Cupri A, Perrone T, De Risi C, Pastore D, Guarini A, Mengarelli A, Benedetti F, Mazza P, Capria V, Chiusolo P, Cupelli L, Federico V, Bozzoli V, Messa AR, Codega P, Bonizzoni E, Specchia G (2020) Efficacy and safety of multiple doses of NEPA without dexamethasone in preventing nausea and vomiting induced by multiple-day and high-dose chemotherapy in patients with non-Hodgkin's lymphoma undergoing autologous hematopoietic stem cell transplantation: a phase IIa, multicenter study. Bone Marrow Transplant 55:2114-2120

15. Dranitsaris G, Molassiotis A, Clemons M, Roeland E, Schwartzberg L, Dielenseger P, Jordan K, Young A, Aapro M (2017) The development of a prediction tool to identify cancer patients at high risk for chemotherapy-induced nausea and vomiting. Ann Oncol 28:1260-1267

16 Giralt S (2010) $200 \mathrm{mg} / \mathrm{m}(2)$ melphalan-the gold standard for multiple myeloma. Nat Rev Clin Oncol 7:490-491 
17. Giralt SA, Mangan KF, Maziarz RT, Bubalo JS, Beveridge R, Hurd DD, Mendoza FL, Rubenstein EB, DeGroot TJ, Schuster MW (2011) Three palonosetron regimens to prevent CINV in myeloma patients receiving multiple-day high-dose melphalan and hematopoietic stem cell transplantation. Ann Oncol 22:939-946

18. Gonullu G, Demircan S, Demirag MK, Erdem D, Yucel I (2012) Electrocardiographic findings of palonosetron in cancer patients. Support Care Cancer 20:1435-1439

19. Hesketh PJ, Rossi G, Rizzi G, Palmas M, Alyasova A, Bondarenko I, Lisyanskaya A, Gralla RJ (2014) Efficacy and safety of NEPA, an oral combination of netupitant and palonosetron, for prevention of chemotherapy-induced nausea and vomiting following highly emetogenic chemotherapy: a randomized dose-ranging pivotal study. Ann Oncol 25:1340-1346

20. Isoda A, Saito R, Komatsu F, Negishi Y, Oosawa N, Ishikawa T, Miyazawa Y, Matsumoto M, Sawamura M, Manaka A (2017) Palonosetron, aprepitant, and dexamethasone for prevention of nausea and vomiting after high-dose melphalan in autologous transplantation for multiple myeloma: a phase II study. Int J Hematol 105:478-484

21 Jordan K, Jahn F, Jahn P, Behlendorf T, Stein A, Ruessel J, Kegel T, Schmoll HJ (2011) The NK-1 receptor-antagonist aprepitant in high-dose chemotherapy (high-dose melphalan and high-dose T-ICE: paclitaxel, ifosfamide, carboplatin, etoposide): efficacy and safety of a triple antiemetic combination. Bone Marrow Transplant 46:784-789

22 Larsen J, Nordstrom G, Ljungman P, Gardulf A (2004) Symptom occurrence, symptom intensity, and symptom distress in patients undergoing high-dose chemotherapy with stem-cell transplantation. Cancer Nurs 27:55-64

23. Lopez-Jimenez J, Martin-Ballesteros E, Sureda A, Uralburu C, Lorenzo I, del Campo R, Fernandez C, Calbacho M, GarciaBelmonte D, Fernandez G (2006) Chemotherapy-induced nausea and vomiting in acute leukemia and stem cell transplant patients: results of a multicenter, observational study. Haematologica 91:84-91

24. Martino M, Olivieri A, Offidani M, Vigna E, Moscato T, Fedele R, Montanari M, Console G, Gentile M, Messina G, Irrera G, Morabito F (2013) Addressing the questions of tomorrow: melphalan and new combinations as conditioning regimens before autologous hematopoietic progenitor cell transplantation in multiple myeloma. Expert Opin Investig Drugs 22:619-634

25. Mirabile A, Celio L, Magni M, Bonizzoni E, Gianni AM, Di Nicola M (2014) Evaluation of an every-other-day palonosetron schedule to control emesis in multiple-day high-dose chemotherapy. Future Oncol 10:2569-2578

26. Musso M, Scalone R, Crescimanno A, Bonanno V, Polizzi V, Porretto F, Bianchini C, Perrone T (2010) Palonosetron and dexamethasone for prevention of nausea and vomiting in patients receiving high-dose chemotherapy with auto-SCT. Bone Marrow Transplant 45:123-127

27. Navari RM (2003) Pathogenesis-based treatment of chemotherapy-induced nausea and vomiting-two new agents. J Support Oncol 1:89-103

28. Passweg JR, Baldomero H, Chabannon C, Basak GW, Corbacioglu S, Duarte R, Dolstra H, Lankester AC, Mohty M, Montoto S, Peffault de Latour R, Snowden JA, Styczynski J, Yakoub-Agha I, Kroger N, European Society for B, Marrow T (2020) The EBMT activity survey on hematopoietic-cell transplantation and cellular therapy 2018: CAR-T's come into focus. Bone Marrow Transplant $55: 1604-1613$
29. Pastore D, Bruno B, Carluccio P, De Candia MS, Mammoliti S, Borghero C, Chierichini A, Pavan F, Casini M, Pini M, Nassi L, Greco R, Tambaro FP, Stefanoni P, Console G, Marchesi F, Facchini L, Mussetti A, Cimminiello M, Saglio F, Vincenti D, Falcioni S, Chiusolo P, Olivieri J, Natale A, Faraci M, Cesaro S, Marotta S, Proia A, Donnini I, Caravelli D, Zuffa E, Iori AP, Soncini E, Bozzoli V, Pisapia G, Scalone R, Villani O, Prete A, Ferrari A, Menconi M, Mancini G, Gigli F, Gargiulo G, Bruno B, Patriarca F, Bonifazi F (2020) Antiemetic prophylaxis in patients undergoing hematopoietic stem cell transplantation: a multicenter survey of the Gruppo Italiano Trapianto Midollo Osseo (GITMO) transplant programs. Ann Hematol 99:867-875

30. Razvi Y, Chan S, McFarlane T, McKenzie E, Zaki P, DeAngelis C, Pidduck W, Bushehri A, Chow E, Jerzak KJ (2019) ASCO, NCCN, MASCC/ESMO: a comparison of antiemetic guidelines for the treatment of chemotherapy-induced nausea and vomiting in adult patients. Support Care Cancer 27:87-95

31. Schakman O, Gilson H, Thissen JP (2008) Mechanisms of glucocorticoid-induced myopathy. J Endocrinol 197:1-10

32 Schmitt T, Goldschmidt H, Neben K, Freiberger A, Husing J, Gronkowski M, Thalheimer M, le Pelzl H, Mikus G, Burhenne J, Ho AD, Egerer G (2014) Aprepitant, granisetron, and dexamethasone for prevention of chemotherapy-induced nausea and vomiting after high-dose melphalan in autologous transplantation for multiple myeloma: results of a randomized, placebo-controlled phase III trial. J Clin Oncol 32:3413-3420

33. Tendas A, Marchesi F, Mengarelli A, Annibali O, Tomarchio V, Saltarelli D, Chierichini A, Di Venanzio M, Sollazzo F, Piedimonte M, Cupelli L, Bruno A, De Angelis G, Delbono L, Niscola P, Perrotti AP, de Fabritiis P, Arcese W, Rome Transplant N (2019) Prevention of chemotherapy-induced nausea and vomiting after high-dose melphalan and stem cell transplantation: review of the evidence and suggestions. Support Care Cancer 27:793-803

34 Tendas A, Niscola P, Perrotti A, Dentamaro T, de Fabritiis P, Arcese W, Rome Transplant Network Quality of Life Working P (2015) Chemotherapy induced nausea and vomiting in bone marrow transplant: the unmet need. Support Care Cancer 23:2211

35. Tendas A, Sollazzo F, Bruno A, Cupelli L, Niscola P, Pignatelli AC, Dentamaro T, de Fabritiis P, Arcese W (2012) Obstacles to managing chemotherapy-induced nausea and vomiting in highdose chemotherapy with stem cell transplant. Support Care Cancer 20:891-892

36. Trifilio S, Welles C, Seeger K, Mehta S, Fishman M, McGowan K, Strejcek K, Eiten E, Pirotte C, Lucier E, DeFrates S, Mehta J (2017) Olanzapine reduces chemotherapy-induced nausea and vomiting compared with aprepitant in myeloma patients receiving high-dose melphalan before stem cell transplantation: a retrospective study. Clin Lymphoma Myeloma Leuk 17:584-589

37. Uchida M, Ikesue H, Miyamoto T, Kato K, Suetsugu K, Ichinose K, Hiraiwa H, Sakurai A, Takenaka K, Muta T, Iwasaki H, Teshima T, Shiratsuchi M, Egashira N, Akashi K, Oishi R (2013) Effectiveness and safety of antiemetic aprepitant in Japanese patients receiving high-dose chemotherapy prior to autologous hematopoietic stem cell transplantation. Biol Pharm Bull 36:819-824

Publisher's note Springer Nature remains neutral with regard to jurisdictional claims in published maps and institutional affiliations. 